\title{
Correlation of Hypoechoic Lesions in Trans-rectal Ultrasound of Prostate with Histopathology in Prostate Cancer
}

\author{
Dinesh Chataut', Babin Basnet ${ }^{2}$, Benu Lohani', Sundar Suwal', Sharma Paudel', Prakash Kayastha ${ }^{1}$ \\ 'Department of Radiodiagnosis and Imaging, Tribhuvan University Teaching Hospital, Kathmandu, Nepal, \\ 2Department of Radiology, Nepal Mediciti Hospital, Lalitpur, Nepal
}

\section{Corresponding author:}

Sundar Suwal, MBBS, MD

Department of Radiodiagnosis and Imaging, Tribhuvan University Teaching Hospital, Kathmandu, Nepal

Email:sundarsuwal@iom.edu.np

Submitted : May 27, 2020

Accepted : Jul 19, 2020

\begin{abstract}
Introduction

Prostate cancer is one of the most common cancer in elderly male. Suspicion of prostate cancer is based on increased Prostate Specific Antigen (PSA) level and abnormal digital rectal examination (DRE) findings. Transrectal ultrasonography (TRUS) can detect and localize hypoechoic lesions in prostate which are considered as suspicious for malignancy. TRUS can also guide for prostate biopsy, which is the gold standard for diagnosis of prostate cancer. The study was aimed to find out TRUS findings in suspected prostate cancer patients and correlate these findings with histopathological findings.
\end{abstract}

\section{Methods}

Prospective study was done in 66 males of age $>40$ years, sent for prostate biopsy in suspicion for prostate cancer (PSA >4 ng/ml, and/or abnormal DRE findings). Prostate was evaluated with TRUS and subsequently underwent TRUS guided six core biopsy of prostate. Total 396 cores of biopsy were taken. Histopathology reports were collected and correlated with the TRUS findings.

\section{Results}

Twenty three patients were positive for prostate cancer and 14 of them showed hypoechoic lesions in TRUS. Total 81 suspicious hypoechoic lesions were seen in prostate of all the patients and among them 42 lesions matched with histopathology report for cancer. Cancerous focus detection rate of TRUS was $51.85 \%$.

\section{Conclusion}

TRUS is a supplementary tool in diagnosis of prostate cancer, however when used alone it has less sensitivity for detection of prostate cancer.

Keywords: Biopsy, prostate cancer, transrectal ultrasonography 


\section{INTRODUCTION}

$\mathrm{P}$ rostate cancer (PCa) is the second most common cancer worldwide, commonly seen in elderly male. ${ }^{1}$ The key to successful treatment of prostate cancer is its early detection. Suspicion of prostate cancer is based on prostate specific antigen (PSA) and digital rectal examination (DRE). However, definitive diagnosis is made with biopsy, and TRUS guided biopsy is the Gold standard. 2,3,4

Watanabe et al first introduced clinical application of TRUS and subsequently hypoechoic lesion defined ultrasound criterion for prostate cancer. ${ }^{3}$ There are many clinical applications of TRUS, including early detection and possible screening of prostate cancer, TRUS guided biopsy, placement of various treatment sources and determination of response to various treatment modalities. TRUS can detect non-palpable prostate cancer and help in guiding the needle for biopsy which increases yield of the biopsy. ${ }^{5}$

There are many controversies regarding PSA screening and DRE has shown to be relatively inaccurate as it underestimates tumor burden.., 6 Thus, majority of patients can present with advanced disease on diagnosis based on these two criterions only. TRUS, as it can help in detecting and localizing prostate cancer, when added can increase the accuracy of PSA and DRE in detecting early prostate cancer.

Although there are studies of role of PSA and DRE in detection of prostate cancer in Nepal, till date no study of role of TRUS for prostate cancer is available in Nepal. This study was aimed to find out TRUS findings of suspected prostate cancer and correlation of suspicious hypoechoic lesions with the histopathology in a tertiary hospital of Nepal.

\section{METHODS}

Hospital based prospective study was done in Department of Radiodiagnosis and Imaging, Tribhuvan University Teaching Hospital during a period of October 2015 to September 2016. Patients with clinical suspicion of prostate cancer referred for TRUS guided biopsy underwent evaluation of prostate with TRUS using C10-3v Curved Linear Endocavity probe of Philips iU22 ultrasound machine in Ultrasonography unit of the Department. Approval of ethical clearance was obtained from Institutional Review Board (IRB), Institute of medicine (IOM). The subjects were explained about the study and a written informed consent was obtained from each patient.

Patients above 40 years of age with increased serum PSA level (>4 $\mathrm{ng} / \mathrm{ml}$ ) and/or abnormal DRE findings were included in the study. For the ultrasound examination, the patients were made to lie in left lateral position as for DRE examination. Then
TRUS was performed for examination of prostate capsule, symmetry, internal echoes and boundary. Any suspicious hypoechoic lesion on TRUS was recorded. Vascularity of the lesion was assessed with color Doppler. Following TRUS evaluation, six core biopsy were obtained from prostate under TRUS guidance. Six core biopsy technique was chosen as it was initial experience of prostate biopsy in this institute. Six cores of biopsy were taken from base, mid zone and apex on both sides (right and left) of prostate. If suspicious hypoechoic lesion seen on TRUS, the lesion was included in the six core biopsy.

Data obtained were compiled and analyzed using standard statistical analyses (SPSS version 16 and Microsoft Excel). Correlation between TRUS and histopathology were done by Odds ratio and cross tabulation. Correlation between serum PSA, TRUS and biopsy findings was done by ANOVA.

\section{RESULTS}

A total of 66 patients with age range of 66 to 88 years were included in the study. Mean age of the patients was $68.9+/-8.7$ years.

Median serum PSA and range of PSA was $11.5 \mathrm{ng} /$ $\mathrm{ml}$ and $4-304 \mathrm{ng} / \mathrm{ml}$ respectively with interquartile range of $8 \mathrm{ng} / \mathrm{ml}$ to $23.5 \mathrm{ng} / \mathrm{ml}$.

Among 66 patients, histopathology showed prostate cancer in 23 patients, thus rate of positivity of prostate cancer in our study was $34.8 \%$. A total of 90 biopsy cores from these 23 patients were positive for cancer.

Thirty five patients had nodular findings of prostate on DRE, however only 12 patients among them had histopathology proven cancer. The cancer detection rate of DRE was $34.3 \%$. (Table 1)

Table 1. DRE findings and biopsy positive among abnormal DRE patients

\begin{tabular}{cccc}
\hline \multicolumn{1}{c}{ DRE findings } & Frequency & $\begin{array}{c}\text { Biopsy } \\
\text { result }\end{array}$ & Number \\
\hline Normal prostate & $31(47 \%)$ & & \\
$\begin{array}{l}\text { Hard and nodular } \\
\text { prostate }\end{array}$ & $35(53 \%)$ & $\begin{array}{c}\text { Negative } \\
\text { Total }\end{array}$ & $(65.7 \%)$ \\
& 66 & & $12(34.3 \%)$ \\
Total & 66 & 35 \\
\hline
\end{tabular}

Eighty one hypoechoic lesions were seen in prostate of these 66 patients. Fifty five hypoechoic lesions were seen in 23 biopsy proven prostate cancer patients. Among these 55 hypoechoic sites, 42 lesions were proven cancer with biopsy. Thus, cancerous foci detection rate of TRUS was $51.85 \%$. Overall, only 14 patients among 23 biopsy proven prostate cancer patients showed hypoechoic lesions in TRUS (60.87\%). The sensitivity, specificity 
Table 2. Correlation of TRUS findings and biopsy with distribution of sites

\begin{tabular}{lcccccc}
\hline \multirow{2}{*}{$\begin{array}{c}\text { TRUS positive } \\
\text { (\%) }\end{array}$} & \multicolumn{6}{c}{ Biopsy positive (\%) } \\
\cline { 2 - 7 } & Right base & Right mid zone & Right apex & Left base & Left mid zone & Left apex \\
\hline Right base & 66.7 & 64.3 & 71.4 & 75.0 & 71.4 & 75.0 \\
Right mid zone & 58.3 & 57.1 & 64.3 & 68.8 & 64.3 & 75 \\
Right apex & 50.0 & 50.0 & 50.0 & 43.8 & 50.0 & 50.0 \\
Left base & 83.3 & 71.4 & 71.4 & 62.5 & 71.4 & 66.7 \\
Left mid zone & 50.0 & 57.1 & 57.1 & 50.0 & 57.1 & 58.3 \\
Left apex & 0.0 & 7.1 & 7.1 & 6.2 & 7.1 & 8.3 \\
\hline
\end{tabular}

Table 3. Correlation of Serum PSA and biopsy

\begin{tabular}{lccccccc}
\hline $\begin{array}{c}\text { Biopsy } \\
\text { findings }\end{array}$ & $\begin{array}{c}\text { Number of } \\
\text { patients }\end{array}$ & $\begin{array}{c}\text { Mean PSA } \\
(\mathrm{ng} / \mathrm{ml})\end{array}$ & $\begin{array}{c}\text { Standard } \\
\text { Error }\end{array}$ & $\begin{array}{c}95 \% \mathrm{Cl} \text { for } \\
\text { Mean }\end{array}$ & $\begin{array}{c}\text { Min PSA } \\
(\mathrm{ng} / \mathrm{ml})\end{array}$ & $\begin{array}{c}\text { Max PSA } \\
(\mathrm{ng} / \mathrm{ml})\end{array}$ & $\mathrm{p}$-value \\
\hline Negative & 43 & 10.26 & 0.762 & $8.72-11.79$ & 4 & 28 & $<0.001$ \\
Positive & 23 & 69.13 & 13.635 & $40.85-97.41$ & 8 & 304 & $<0.001$ \\
Total & 66 & 30.77 & 5.855 & $19.08-42.47$ & 4 & 304 & \\
\hline
\end{tabular}

and accuracy of TRUS in detecting prostate cancer in our study was $46.67 \%, 87.25 \%$ and $73.13 \%$ respectively.

Maximum biopsy positive cores were from base of prostate (right $-66.7 \%$, left $-62.5 \%$ ). (Table 2)

At $95 \% \mathrm{Cl}$ if the value of serum PSA $\leq 8.72 \mathrm{ng} / \mathrm{ml}$ there is significant chance that biopsy of that case will be negative. (Table 3 )

\section{DISCUSSION}

TRUS remains the imaging modality of choice for prostate and common appearance of prostate cancer in TRUS is hypoechoic lesion in peripheral zone. However, not all hypoechoic lesions are cancers and not all cancers appear as hypoechoic lesions. ${ }^{7,8}$ Thus, American College of Radiology and American Cancer Society have recommendedTRUS evaluation of prostate to be limited to patients with either raised PSA level or abnormal DRE. ${ }^{9}$

Among 66 patients 23 patients were diagnosed as prostate cancer by histopathology with rate of positivity of prostate cancer as $34.8 \%$ which was comparable with the rate of positivity of prostate cancer of the study done by Tomoaki Miyagawa et $\mathrm{al}^{10}$ and Pallwein $\mathrm{L}$ et $\mathrm{al}^{2}$ where rate of positivity of prostate cancer were $30.5 \%$ and $35 \%$ respectively but the rate of positivity of prostate cancer was low as compared to the study done by Yan Z et al (57\%) and Nelson ED et al (43.8\%).11,12 The difference could be because of geographic difference in prevalence of the prostate cancer.

Thirty patients had hard and nodular prostate on DRE and among them 12 were positive for prostate cancer in histopathology. Prostate cancer detection rate of DRE was $34.3 \%$ which was comparable to the study done by Tomoaki Miyagawa et al (37.8\%). ${ }^{10}$
Among 23 biopsy proven prostate cancer patients, hypoechoic lesions were seen in $60.8 \%$ patients, which is higher as compared to the study done by Ganie et al (41.5\%). However, cancerous focus detection rate in our study was $51.85 \%$ only. Ganie et al also found $14.1 \%$ of biopsy proven prostate cancer had isoechoic lesions and 5.07\% had hyperechoic lesions, which were not included in this study. ${ }^{3}$

Cancer detection rate of PSA and DRE in our study were $34.85 \%$ and $34.3 \%$ respectively, which is lower as compared to cancer detection rate of TRUS (51.85\%). Thus, presence of TRUS detectable lesion significantly increases likelihood of cancer detection. ${ }^{13}$ However, TRUS is still limited in prostate cancer detection due to variable ultrasound appearances (including iso to hyperechoic cancers mimicking benign lesions), poor specificity of various sonographic manifestations in prostate cancer, and multifocal nature of the prostate cancer. ${ }^{14}$ Under-detection of prostate cancer in anterior aspect can also occur in the background of benign prostatic hyperplasia. ${ }^{7}$ Further application of modern imaging technology like elastography can improve sensitivity and accuracy of TRUS for detection of prostate cancer. Also, smaller sample size and non-inclusion of isoechoic and hyperechoic lesions were our limitations of this study.

\section{CONCLUSION}

TRUS is a supplementary tool in diagnosis of prostate cancer for its detection, localization and guidance for biopsy. Although TRUS detectable lesions in prostate significantly increase the cancer detection rate, TRUS alone is less sensitive for detection of prostate cancer. 


\section{CONFLICT OF INTEREST}

None declared.

\section{REFERENCES}

1. Siegel R, Miller K, Jemal A. Cancer statistics, 2016. CA: A Cancer Journal for Clinicians. 2016;66(1):7-30.

2. Pallwein $L$, Mitterberger $M$, Struve $P$, et al. Real-time elastography for detecting prostate cancer: preliminary experience. BJU International. 2007;100(1):42-6.

3. Ganie FA, Wanie MS, Ganie SA, et al. Correlation of transrectal ultrasonographic findings with histo pathology in prostatic cancer. Journal of Education and Health Promotion [Internet]. 2014 May $5 ; 3: 38$.

4. Lopes PM, Sepúlveda L, Ramos R, et al. The role of transrectal ultrasound in the diagnosis of prostate cancer: new contributions. Radiolia Brasileira [Internet]. 2015;48(1):7-11.

5. Lee F, Torp-Pedersen S, Siders D. The role of transrectal ultrasound in the early detection of prostate cancer. CA: A Cancer Journal for Clinicians. 1989;39(6):337-60.

6. Yacoub JH, Verma S, Moulton JS, et al. Imaging-guided Prostate Biopsy: Conventional and Emerging Techniques. RadioGraphics [Internet]. 2012 May 1;32(3):819-37.

7. Harvey CJ, Pilcher J, Richenberg J, et al. Applications of transrectal ultrasound in prostate cancer. The British Journal of Radiology [Internet]. 2012/07/27. 2012 Nov;85 Spec No(Spec Iss 1):S3-17.

8. Rietbergen JBW, Schröder FH. Screening for Prostate Cancer - More Questions than Answers. Acta Oncoligica (Madr) [Internet]. 1998 Jan 1;37(6):515-32.

9. Littrup P, Bailey S. Prostate cancer: the role of transrectal ultrasound and its impact on cancer detection and management. Radiology Clinics of North America. 2000;38(1).

10. Miyagawa $T$, Tsutsumi M, Matsumura $T$, et al. Real-time Elastography for the Diagnosis of Prostate Cancer: Evaluation of Elastographic Moving Images. Japanese Journal Clinical Oncology. 2009 May 1;39:394-8.

11. Yan Z, Jie T, Yan-Mi L, et al. Role of transrectal real-time tissue elastography in the diagnosis of prostate cancer. Acta Academiae Medicinae Sinicae. 2011;33(2):175-9.

12. Nelson ED, Slotoroff CB, Gomella $L G$, et al. Targeted biopsy of the prostate: the impact of color Doppler imaging and elastography on prostate cancer detection and Gleason score. Urology. 2007;70(6):1136-40.

13. Toi A, Neill MG, Lockwood GA, et al. The continuing importance of transrectal ultrasound identification of prostatic lesions. The Journal of Urology. 2007;177(2):516-20.

14. Raja J, Ramachandran N, Munneke G, et al. Current status of transrectal ultrasound-guided prostate biopsy in the diagnosis of prostate cancer. Clinical Radiology. 2006;61(2):142-53. 